\title{
AHP-GP Approach by Considering the Leopold Matrix for Sustainable Water Reuse Allocation: Najafabad Case Study, Iran
}

\author{
Behnam Fooladi Dehaghi', Ali Khoshfetrat ${ }^{1,2^{*}}$ \\ ${ }^{1}$ Department of Civil Engineering, Najafabad Branch, Islamic Azad University, Najafabad, Iran \\ ${ }^{2}$ Water Studies Research Center, Isfahan (Khorasgan) Branch, Islamic Azad University, Isfahan, Iran \\ * Corresponding author, e-mail: khoshfetrat@khuisf.ac.ir
}

Received: 03 August 2019, Accepted: 03 March 2020, Published online: 06 April 2020

\begin{abstract}
Water reuse allocation is one of the major challenges in water resource management which requires the assessment of water reuse alternatives, especially in regions with limitation in water resources, arid climates, population growth and increasing water demand. Considering the complexity of the problem, water reuse allocation by using conventional methods for maximizing benefits, minimizing cost and environmental risks, cannot guarantee optimal allocation. In this paper, Analytic Hierarchy Process (AHP) which can be combined with Goal Programming (GP) by considering the Leopold matrix for carrying-out the Environmental Impact Assessment (EIA) is used for sustainable water reuse allocation for multiple stakeholders in Najafabad as a case study. The results show that the developed mathematical model with combination of quantitative evaluation and optimization can be considered as an effective and flexible tool for creating better guidelines to adapt the requirements of various stakeholders for better allocation of recycled water. Finally, based on sensitivity analysis in AHP, a What-If analysis in GP is performed to the robustness of the final results of water reuse allocation.
\end{abstract}

Keywords

AHP, EIA, GP, water reuse allocation, Najafabad

\section{Introduction}

Water reuse as an alternative source of water has grown throughout the world, and the global approach reflects increasing application of this unconventional approach in many countries as a way to deal with water scarcity problems. The basic purpose of water resources management is to reduce the level of risk acceptance and increase the social, health and economic benefits. The issue of optimal allocation of water resources has been promoted due to limited water resources and unlimited stakeholders' needs for water resources.

Using an optimization approach can handle the system's analysis process and lead to transparent, sustainable and cost-effective feasible plans [1]. Combination of Multiattribute decision making (MADM) which are commonly used to assess potential weights of alternatives with MultiObjective Programming (MOP) approaches can be applied to find an optimal solution that could handle the management of limited resources such as water resources. As examples, Sharma and Balan [2] used AHP-GP model to select the best supplier and Aznar et al. [3], and Ostadhashemi et al. [4] used AHP-GP model for optimizing the appropriate plantation area for each species and agricultural valuation.

MADM approaches are widely used in various applications whose purpose is to select the most appropriate of different alternatives or to assess potential weighting of alternatives to support decision making in allocation problems on the basis of known criteria of a limited number of alternatives. The MADM method is one of the MultiCriteria Decision Making (MCDM) categories that have a small and finite group of solutions based on number of feasible ones $[5,6]$. Some of the MADM's selection criteria are: ability to sensitivity analysis and performance evaluation, flexibility, compatibility with other programs for optimal allocation and simplicity application. AHP, analytic network process (ANP), utility additive (UTA) and TODIM are some of basic methods under the MADM category [7]. A main drawback of the MADM approaches such as AHP method is the uncertainty problem that is 
imported from the pairwise comparison matrix, which includes some uncertain factors ordinary to environmental matters [8,9], based on change of criteria weights of alternatives in the AHP method sensitivity analysis and the change of final alternative weights can be studied.

A major issue of debate within the MOP community has concerned the use of normalization scheme for avoiding pitfalls in formulations [10, 11]. In AHP technique, the alternative weights use a normalization scheme, so this method can handle hybrid MOP and allocation problems.

The GP method introduced by Charnes and Cooper [12] is a tool for eliminating the impossible situation caused due to contradiction in goals in linear programming issues [13]. Tamiz et al. [10] later developed it by presenting GP method properties and applications. GP method is the best choice when handling a set of opposing objectives which require approval of specific thresholds or objective values according to priority sequence or their importance in the view of decision-maker that should focus their efforts to achieve a satisfactory level of goals [14].

Gomes et al. [14] and Díaz-Balteiro and Romero [15] used GP in order to determine the optimal forest management. Samghabodi et al. [16] and Chang et al. [17] developed a GP model for planning a watershed and solving a project selection problem.

Water resource problems are human problems and cannot be solved without comprehension the human factor behind $[18,19]$. Kardoss [18] EIA in the design procedure force the designers to attract more notice to the social environment and natural. A detailed understanding of EIA is important as an effective license for implementing civil engineering projects in assessing environmental impacts before developing any project and its position in comprehensive decision-making [20]. EIA is a well-known legal process for predicting the positive or negative environmental impacts of a project before deciding on developing and implementing a plan and it is a process that collects information about the environmental impacts of a development plan and, by evaluating its effects, can take actions to adjust the effects to an acceptable level or to review new technology solutions [21].

In the context of water reuse management, Keremane and McKay [22] planned water reuse schemes for sustainable development by environmental and socio-economic dimensions. Gikas et al. [23] used optimization model based on mixed integer linear programming for calculating the financial benefits of water reuse. Lee et al. [24] performed an optimization framework that optimizes the water reuse and renewable energy resources in buildings. Mcheik et al. [25] used the results of several scenarios in reuse of treated municipal wastewater for table grapes irrigation in Jordan.

So far, the combination of MADM with MOP approaches has not been used to obtain an optimal allocation of recycled water in the context of water reuse management. This paper presents an AHP method for weighting of urban water reuse criteria and alternatives which is capable to be combined with MOP methods such as goal programming (GP) by considering the Leopold matrix for carrying-out the Environmental Impact Assessment (EIA).

Combined method is an approach that can provide deeper, wider and more useful knowledge and information of the problem. It can also reduce the personal biases of decision-makers and provide complementary information to increase credibility and confidence of the results. In this paper, a case study that deals with water reuse allocation is presented to show the effectiveness of the AHP method in combination with GP model by considering the Leopold matrix for carrying-out the EIA by the demonstrative application in Najafabad region. On the other hand, the weighting of water reuse criteria and alternatives from the AHP and quantitative environmental impacts from the Leopold matrix output values based on sustainability criteria presented in the UN Sustainable Development Goals (SDGs), also termed as the Global Goals [26] are combined with the GP model as coefficients of goals and objective function, then this model is used to calculate the amount of water reuse allocation. Finally, stability of the solution evaluated based on sensitivity analysis in AHP and What-If analysis in GP models.

\section{The study region}

Najafabad plain is one of sub-basins of the Zayandehrud River basin in the west of Isfahan province with an area of $1712 \mathrm{~km}^{2}$. Its minimum and maximum altitudes are 1580 and $2925 \mathrm{~m}$, respectively. Najafabad plain is situated between $32^{\circ} 20^{\prime}$ to $32^{\circ} 49^{\prime} \mathrm{N}$ latitude and $50^{\circ} 57^{\prime}$ to $51^{\circ} 44^{\prime} \mathrm{E}$ longitude. Fig. 1 shows the location of Najafabad plain and its irrigation networks.

\subsection{Water resources}

In Najafabad basin during the decay years, despite growing water demand, due to climate changes, the decline or groundwater and surface water has created a crisis. Therefore, water reuse management is essential for managing water resources and organizing the urban water supply situation. 


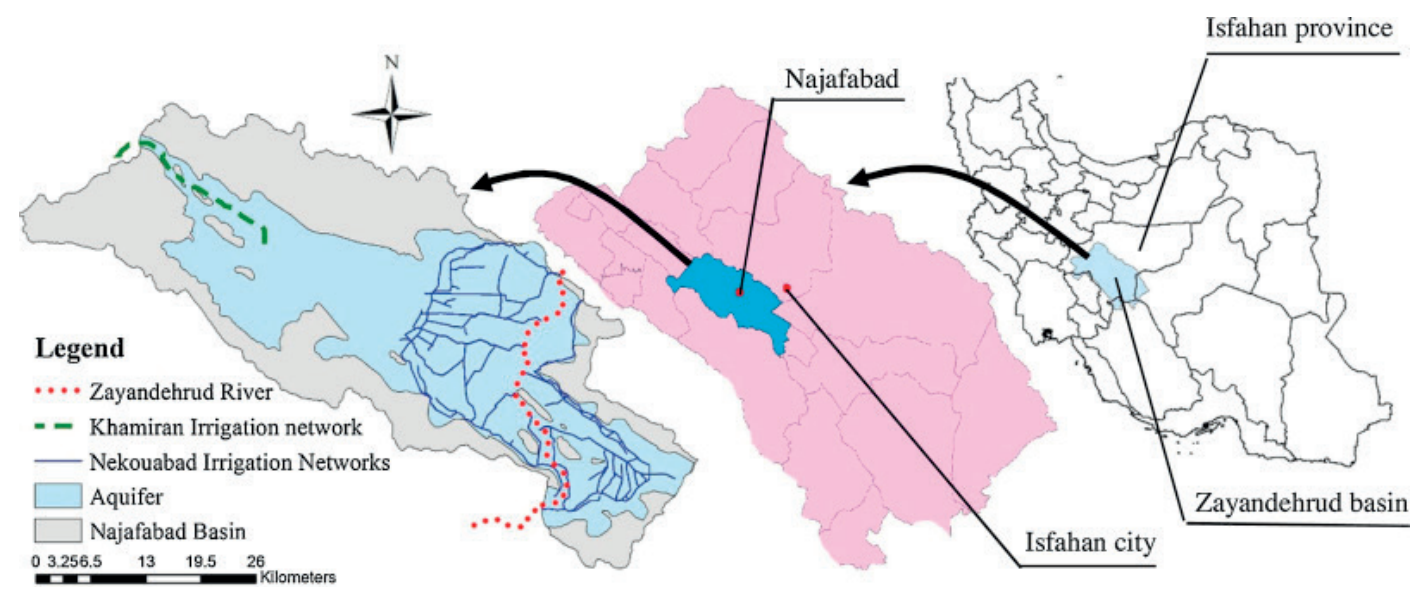

Fig. 1 Location of Najafabad Plain and the irrigation networks

\subsubsection{Groundwater}

Najafabad aquifer has an area of $932 \mathrm{~km}^{2}$ with an average thickness of $69 \mathrm{~m}$ (30-120 m). Fig. 2 shows the cumulative mean of piezometric level changes in its aquifer for a 34-year time period. The general characteristics of Najafabad aquifer are presented in Table 1.

Najafabad aquifer is recharged by direct precipitation, seepage from the local water channels and the river, irrigation percolation and transitional flow. The recharge and discharge are estimated to be about 1260 and 1398 million cubic meters (MCM) per year, respectively. Storage changes in the aquifer is about $-138(\mathrm{MCM})$ per year that

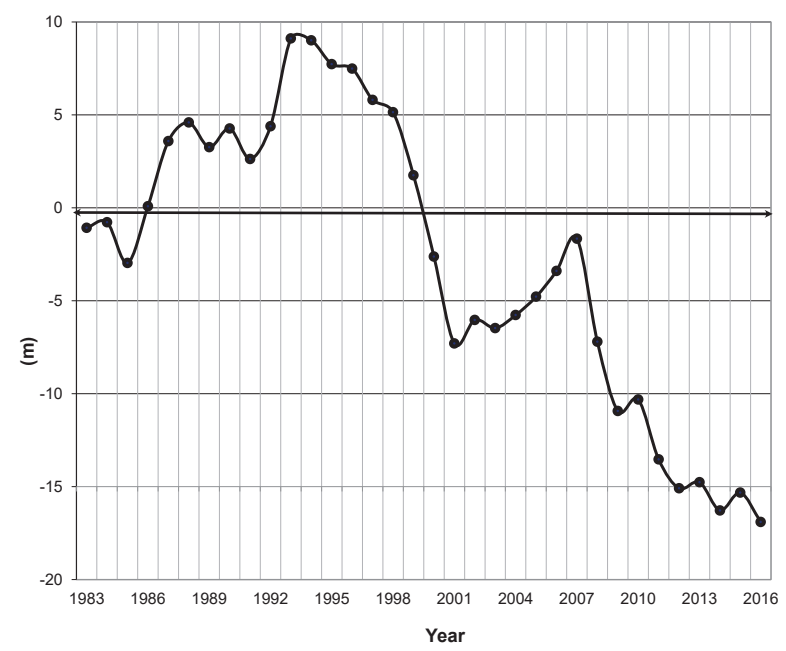

Fig. 2 Cumulative mean of piezometric level changes in Najafabad aquifer for a 34-year time period [27] indicates an imbalance between recharging and discharging in this aquifer. Table 2 shows hydrological cycle in Najafabad plain (MCM) per year.

\subsubsection{Surface water}

Zayandehrud River is the most important surface water resource in the west of Najafabad region with length of $36 \mathrm{~km}$. In recent years, despite increasing pressure of water demand due to climate changes, the severe drought and low-rainfall year, water has become increasingly scarce. Fig. 3(a) shows the monthly variation of long-term period discharge and Fig. 3(b) illustrates the annual discharge values over the last 21 years for Mousian hydrometric station along the Zayandehrud River from October 1996 to September 2016. The mean annual discharge in long-term period is approximately $180 \mathrm{~m}^{3} \mathrm{~s}^{-1}$.

\subsubsection{Potential for water reuse}

Najafabad wastewater treatment plant is the main treatment plant in the south of Najafabad city. Effluent of this plant can be considered as a new strategy that can respond to part of this problem. The total population of Najafabad city was about 235,281 in 2016 [28]. Based on the population growth in previous years, the predicted water consumption per capita and the population for the next 25 years, the amount of wastewater production is estimated as an average of about $420 \mathrm{ls}^{-1}$. Table 3 shows main features of wastewater collection and treatment plant in the

Table 1 General characteristics of Najafabad aquifer (ground water resources) [27]

\begin{tabular}{lccccc} 
& \multicolumn{2}{c}{ Aquifer } & \multicolumn{2}{c}{ Specific storage (\%) } & \multicolumn{2}{c}{ Average piezometric level } \\
Sub-basin & $\begin{array}{c}\text { Average thickness } \\
(\mathrm{m})\end{array}$ & $\begin{array}{c}\text { Max. water storage } \\
\text { capability (MCM) }\end{array}$ & $\begin{array}{c}\text { Unconfined (U.C.) } \\
\text { Confined (C) }\end{array}$ & $\begin{array}{c}\text { Beginning of } \\
\text { period (Oct. 1991) }\end{array}$ & $\begin{array}{c}\text { End of period } \\
\text { (Sep. 2016) }\end{array}$ \\
\hline Najafabad & 69 & 3297 & 2 & - & 19.9 \\
\hline
\end{tabular}


Table 2 Hydrological cycle in Najafabad plain (MCM) per year [27]

\begin{tabular}{|c|c|c|c|c|c|c|c|c|c|c|c|c|c|c|c|}
\hline \multicolumn{6}{|c|}{ Recharge } & \multicolumn{8}{|c|}{ Discharge } & \multicolumn{2}{|c|}{ Storage changes } \\
\hline \multicolumn{2}{|c|}{ Precipitation } & \multirow{2}{*}{ 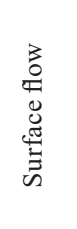 } & \multirow{2}{*}{ 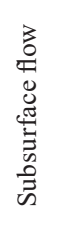 } & \multirow{2}{*}{ 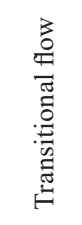 } & \multirow{2}{*}{ 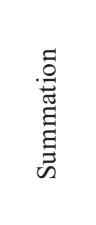 } & \multicolumn{4}{|c|}{ Evapotranspiration } & \multirow{2}{*}{ 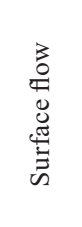 } & \multirow{2}{*}{ 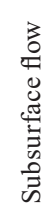 } & \multirow{2}{*}{ 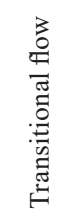 } & \multirow{2}{*}{ 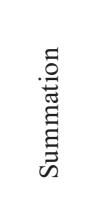 } & \multirow{2}{*}{ 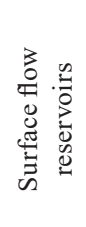 } & \multirow{2}{*}{ 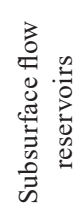 } \\
\hline 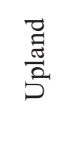 & Plain & & & & & 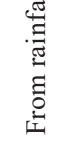 & 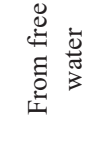 & 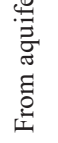 & 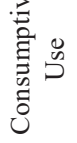 & & & & & & \\
\hline 132.4 & 165.3 & 557.4 & 14.7 & 390.6 & 1260.5 & 217.6 & 2.3 & 0.9 & 732 & 380.5 & 0 & 65.2 & 1398.4 & - & -138 \\
\hline
\end{tabular}

Table 3 Main features of wastewater collection and treatment system in Najafabad city

\begin{tabular}{|c|c|c|c|c|c|c|c|c|c|}
\hline \multirow{2}{*}{$\begin{array}{l}\text { Name of } \\
\text { city }\end{array}$} & \multicolumn{2}{|c|}{ Population } & \multicolumn{2}{|c|}{$\begin{array}{c}\text { Wastewater collection } \\
\text { system }(\mathrm{km})\end{array}$} & \multirow{2}{*}{$\begin{array}{l}\text { Diameter of } \\
\text { wastewater } \\
\text { collection } \\
\text { system } \\
(\mathrm{mm})\end{array}$} & \multicolumn{3}{|c|}{$\begin{array}{l}\text { Treatment system capacity } \\
\text { (Number of people) }\end{array}$} & \multirow{2}{*}{$\begin{array}{l}\text { Wastewater } \\
\text { treatment method }\end{array}$} \\
\hline & $\begin{array}{l}\text { Beginning } \\
\quad(2016)\end{array}$ & $\begin{array}{l}\text { project period } \\
(2040)\end{array}$ & $\begin{array}{l}\text { designed } \\
\quad(\mathrm{km})\end{array}$ & $\begin{array}{l}\text { erected } \\
(\mathrm{km})\end{array}$ & & $\begin{array}{c}\text { Module1 } \\
\text { (Constructed) }\end{array}$ & $\begin{array}{c}\text { Module2 } \\
\text { (designed) }\end{array}$ & $\begin{array}{l}\text { Module3 } \\
\text { (designed) }\end{array}$ & \\
\hline Najafabad & 235,281 & 350,000 & 527 & 220 & $200-1400$ & 100,000 & 100,000 & 150,000 & $\begin{array}{c}\text { Lagoon activated } \\
\text { sludge system } \\
\text { (LASS) }\end{array}$ \\
\hline
\end{tabular}

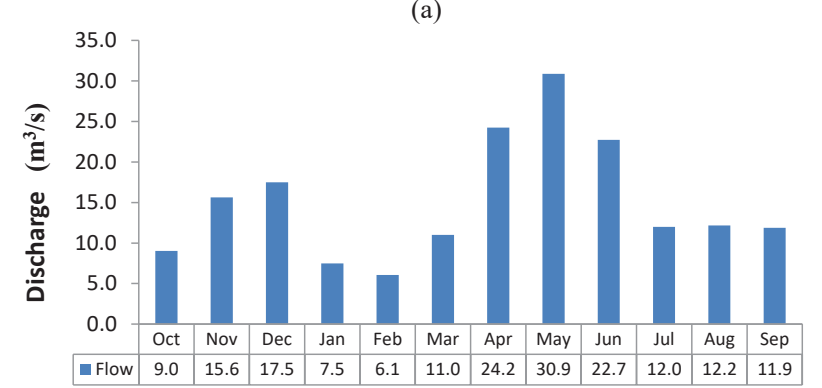

(b) Average of long time discharg $\epsilon$

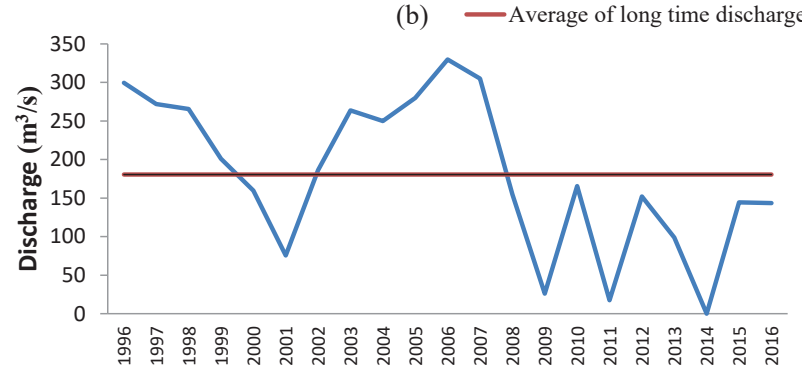

Fig. 3 Variation of the Zayandehrud River discharge in Mousian station: a) variation in monthly flow for a 21 -year time period. b)

Discharge records for each year (Zayandehrud River) [27]

Najafabad city [29]. Due to inadequate government funding, the construction of about $300 \mathrm{~km}$ of the wastewater collection system and modules 2 and 3 of Najafabad wastewater treatment plant will be supplied by pre-sale of recycled water.

\subsection{Alternatives}

Najafabad region is more significant with respect to social, economic, environmental and legal criteria because of the interaction between water resources and development of agriculture, industries and urban population density in these areas. In this case study, based on submitted requests information, three candidates are selected as applicable water reuse alternatives, which are as follows: $\mathrm{T}_{1}$ : Urban landscape irrigation, $\mathrm{T}_{2}$ : Agricultural irrigation, and $\mathrm{T}_{3}$ : Industrial demand.

\subsubsection{Urban landscape irrigation}

The green space irrigation is one of the largest water uses in Najafabad plain that includes landscaped areas around commercial and residences, freeway medians, parks, and playgrounds. Table 4 presents the total amounts of the green space and parks area in Najafabad city. At present, the total area of the green space in Najafabad city is about 260 ha. There are 63 parks with about 120 ha area in Najafabad. The main planted species in the green space are cypress, mulberry, and acacia [30].

\subsubsection{Agriculture irrigation}

The main water user in Najafabad plain is the agriculture sector. The aquifer offers a high potential for agriculture but, in spite of the modern irrigation networks erected in the region, the surface and under-ground water resources are under a great pressure leads to serious water shortage. Table 5 presents the total water requirement for the most important crops in Najafabad plain based on the efficiency of distribution and transmission irrigation systems [31].

\subsubsection{Industrial demand}

Isfahan power plant is the major industry in Najafabad plain. This plant is located in the east of Najafabad Plain. At present, Isfahan power plant has been connected to five 
Table 4 The green space and parks area in Najafabad city

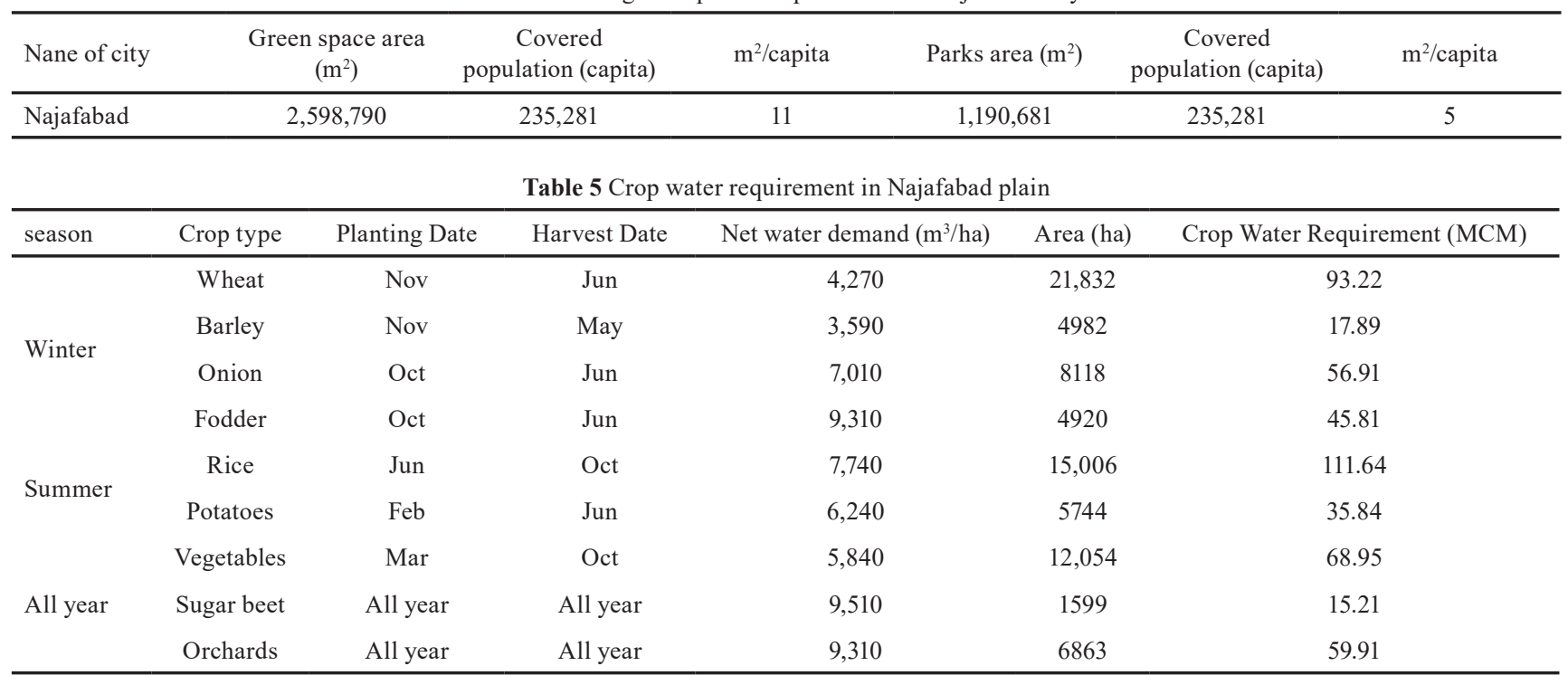

electricity generators with a nominal capacity of $835 \mathrm{MW}$ including two units of 37.5 , one 120 and two $320 \mathrm{MW}$ to the national electricity network. The average amounts of water requirement for cooling and other process in Isfahan power plant is about $260 \mathrm{ls}^{-1}$ [32].

\section{Methodology}

\subsection{Analytic Hierarchy Process (AHP)}

The Analytic Hierarchy Process (AHP) introduced by Saaty [33] is a famous tool for dealing with complex decision-making, pairwise comparison and assignment qualitative input to crisp value that may aid the decision-maker to set priorities and make the best decision. The AHP method leads to capture both subjective and objective aspects of a decision by reducing the complex decisions and synthesizing the results.

At each level of the hierarchy, pairwise comparisons realize the attributes and alternatives relevant weights to each attribute. In addition, the AHP incorporates a useful method for checking the consistency of the decisionmaker's evaluations results in a reduction in the bias in the decision-making process.

Gradation (relative) scales for assessment from one (same importance) to nine (much more important) are used for pairwise comparisons (see Table 6). In addition, the entries of the importance of criterion $\left(a_{i j}\right)$ and $\left(a_{j i}\right)$ must satisfy the $a_{i j} \times a_{j i}=1$ constraint [33]. The algorithm for the AHP method is summarized in the following steps [34]:

Step 1: Foundation decision matrix based on pairwise comparison.
Step 2: Computation of priority (i.e., normalized eigenvector). Equation (1) is used for the normalized decision matrix.

$n_{i j}=\frac{a_{i j}}{\sum_{i=1}^{n} a_{i j}}$,

where $a_{i j}$ is the importance of criterion relative to others, $i$ and $j$ (subjective judgment: see Table 6).

Step 3: Then, Eq. (2) is used to calculate the local weights $\left(W_{k}\right)$.

$W_{k}=\frac{\sum_{i=1}^{n} n_{i j}}{n}$,

where $n_{i j}$ is the normalized eigenvector, $n$ is the total number of criteria.

Step 4: This step is to check that how consistent the judgments is relative to large samples of purely random judgments. So, $(C R)$ is calculated as Consistency Index $(C I)$ divided by Random Index $(R I)$, where $(R I)$ is the average $(C I)$ from random matrices. $(R I)$ values may be different across research studies. Here Alonso and Lamata

\begin{tabular}{lc}
\multicolumn{2}{c}{ Table 6 Gradation scales for assessment in AHP method [33] } \\
\hline Pairwise comparison importance in AHP method $\left(a_{i j}\right)$ & Priority values \\
\hline Equal & 1 \\
Marginally strong & 3 \\
Strong & 5 \\
Very strong & 7 \\
Absolutely strong & 9 \\
Intermediate inputs between adjacent scale value & $2,4,6,8$ \\
\hline
\end{tabular}


used $R I$-values of 0.5245 and 1.1086 for the three water reuse alternatives and five criteria on the pair-comparison matrix, respectively. The $(C R)>0.10$ indicates that there is a concern of inconsistency in pairwise comparison. Eq. (3)

$$
\begin{aligned}
& C R=\frac{C I}{R I} ; C I=\lambda_{\max }-\frac{n}{n-1} ; \lambda_{\max }=\sum_{(i=1)}^{n} P S_{i} / w_{i} / n ; \\
& P S_{i}=\sum_{(i=1)}^{n} q_{i j} / n ; q_{i j}=a_{i j} / w_{i} .
\end{aligned}
$$

Step 5: Eq. (4) is used to calculate the final weight of alternatives $\left(R_{i}\right)$, multiplying relative weight of the criteria into relative weights of the alternatives. Values of $R_{i}=[0-1]$ are used for weighting water reuse alternatives.

$R_{i}=\sum_{i=1}^{k} w_{k} \times r_{i k}$,

where $w_{k}$ is the priority weight of the criterion $k, r_{i k}$ is the normalized value of the criterion $k$ and alternative $(i)$.

Fig. 4 shows the hierarchical structure for weighting the water reuse alternatives.

\subsubsection{Sensitivity analysis}

In AHP method the weights of alternatives are dependent on the priorities of attributes and sensitivity analysis, concept can be studied under variations in the weights of attribute and based on following procedure changes in attribute priorities that obtain of the behavior of DMs can cause changes in the alternative weights.

When the weight of the first attribute is varied from 0 to 1 , the value of the other attributes is recalculated in a way which the ratios between the other weights are kept constant [35].
Suppose that we first interest in varying the weight of the $E_{1}$, Eq. (5) is shown which the sum of all criteria weights is one.

$$
E_{1}+E_{2}+E_{3}+E_{4}+E_{5}=1
$$

When defining $p_{1}=E_{2} / E_{3}, p_{2}=E_{4} / E_{3}, p_{3}=E_{5} / E_{3}$, and inserting $p_{1}-p_{3}$ into Eq. (5), we obtain Eq. (6):

$E_{1}+p_{1} E_{3}+E_{3}+p_{2} E_{3}+p_{3} E_{3}=1$.

In Eq. (7), E3 is a function of $E_{1}$.

$$
E_{3}=\frac{1-E_{1}}{p_{1}+p_{2}+p_{3}+p_{4}+p_{5}}
$$

And Eq. (8) which implies that all other attribute weights are also functions of a single variable $E_{1}$ :

$$
\begin{aligned}
& E_{2}=\frac{p_{1}\left(1-E_{1}\right)}{p_{1}+p_{2}+p_{3}+p_{4}+p_{5}}, E_{4}=\frac{p_{2}\left(1-E_{1}\right)}{p_{1}+p_{2}+p_{3}+p_{4}+p_{5}} \\
& E_{5}=\frac{p_{3}\left(1-E_{1}\right)}{p_{1}+p_{2}+p_{3}+p_{4}+p_{5}},
\end{aligned}
$$

when $E_{1}$ is fix, Eqs. (7) and (8) determined the other attribute weights. Then, these new weights of attributes are used in the procedure of AHP to calculate the new final alternative weights and checking whether $E_{1}$ changes affect the alternative weights. If the weight of $E_{2}$ is changed the similar synthesis is valid.

\subsection{Leopold matrix}

The Leopold matrix developed by Leopold et al. [36], for responding to the US Policy Law of 1969, which provide clear guidelines for state government agencies to produce an EIA report of the projects designed by an organization.

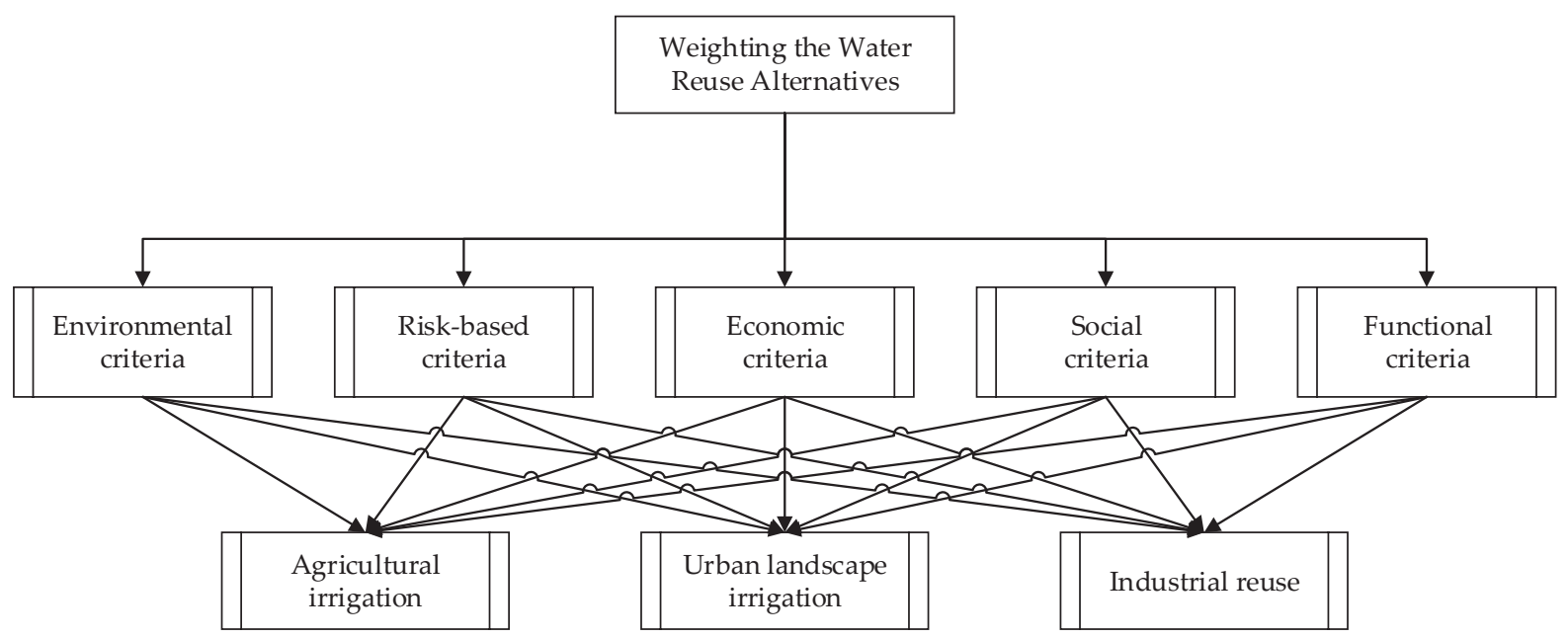

Fig. 4 Hierarchy structure for the water reuse weighting 
The Leopold matrix provides a tool for numerical analysis and weighting evaluation of the significance of possible effects. As noted by the designers of the Leopold matrix, there is a significant ability of using the matrix as a checklist of a wide range of environmental actions and impacts that can be related to the suggested operation [36].

This method evaluated the environmental impacts of each activities in the constructional and operational phase of the project based on the type of activities and it consists of three components as follows: (1) A checklist of the main impacts of activities on the environment in which the proposed operation may be performed, and then the magnitude of each of the impacts is estimated; (2) The assessment of the significance of each of the above mentioned impacts (for example, regional versus global or local); (3) A summary assessment, that is a combination of the importance and magnitude of the effects [37].

Net privilege number for impact $=$ magnitude of effect $\times$ significance of effect.

Equation (9) was used to quantify evaluation in the Leopold matrix. This shows the net privilege number for impact, which is obtained by multiplying of the magnitude in the significance scope of the impact. Summing up all the levels of the effect horizontally and vertically together and finally giving a positive or negative number in the left corner of the matrix, are the basis of judgment [36]. Magnitude of effect is the degree of change due to activities, based on existing facts of environmental parameters and scored from -3 to +3 and significance of the effect is determined by the radius of influence and is defined with the numbers of 0 to 5 .

\subsection{GP and proposed framework for water reuse allocation}

In many cases, decision-maker must achieve more than two objectives where these goals even conflicted simultaneously. A GP model is a format of linear programming model that attempts to optimize the function with multiple objectives. A goal is an objective with a "right hand side", which is a goal value associated with the goal. Undesirable deviation from this set of target values in a success function is minimized. All the objectives are indicated by goal constraints in the same procedure. Goal constraint contains donation variables that determine the amount in which the share of all activities in the goal is exposed to fall behind or exceed the goal level (i.e., the right side of the constraint). The objective function of a GP problem is to minimize the sum of the deviations (weights) of all objective levels associated with management goals. When target variables are constrained, the problem of impossibility associated with the constraint is avoided. The algorithm for the GP method is summarized in the following steps [13]:

Step 1: The decision variables and hard constraints values are formulated in a conventional LP method.

Step 2: The goals along with their target values are converted to goal constraints by using the decision variables that would achieve the goals.

Step 3: Determining which deviational variables represent undesirable deviations of the goals and formulating an objective that penalizes the undesirable deviations.

Step 4: Solve the problem; the deviations can be weighted according to their importance.

Equation (10) shows the objective function of the GP method that seeks to minimize the deviation from goals in the order of the goal priorities [13].

$\operatorname{minz}=\sum_{i=1}^{G}\left(W_{i}^{-} D_{i}^{-}+W_{i}^{+} D_{i}^{+}\right)$

$W_{i}^{+}$is the weight per unit of overachievement deviation $D_{i}^{+}$and $W_{i}^{-}$is the weight per unit of underachievement deviation $D_{i}^{-}$.

In the GP method, the objective function contains some or all of the target variables. Decision-makers may choose larger weights for deviations that are concerned, and when they are not concerned, deviations may be eliminated [38]. This weight selection for objective function can be simplified depending on the relative deviations instead of absolute ones. Equation (11) is shown the new presentation of the objective function.

$$
\operatorname{minz}=\sum_{i=1}^{G}\left(\frac{U_{i}^{-} D_{i}^{-}+U_{i}^{+} D_{i}^{+}}{g_{i}}\right) .
$$

$U_{i}\left(U_{i}^{-}, U_{i}^{+}\right)$is the weight that used to a relative deviation from goal ${ }_{i}$.

Target variables balance the distortion between the levels of management and real purpose. Equation (12) is shown the general purpose of goal constraints [38]: and $T_{j}$, $D_{i}^{+}, D_{i}^{-}>=0$

$\sum_{i=1}^{G} A_{i j} T_{j}+D_{i}^{-}-D_{i}^{+}=g_{i}$, for $i=1, \ldots, M$

$A_{i j}$ is the (constant) contribution to goal $i$ per unit of activity $j, T_{i}$ is the $j^{\text {th }}$ activity (decision) variable and $g_{i}$ is the constant measuring the target of goal $i$, of which there are $M$. 
Equation (13) is shown the usual LP variety of goal constraints [38]:

$$
\sum_{i=1}^{n} A_{i j} T_{j} \leq,=, \geq \text {, for } i=M+1, \ldots, m \text {. }
$$

To minimize the differences, one of deviation is always zero and the other can diverge from zero and reach the target level, to achieve the target level $G_{j}$ for goal $i$, if $D_{i}^{-}$is greater than zero, $D_{i}^{-}$must be added to the left-hand side of the constraint and if $D_{i}^{+}$is greater than zero, to achieve the goal, $D_{i}^{+}$must be subtracted from the left-hand side of the constraint [13].

Fig. 5. illustrated hybrid of AHP, Leopold matrix and post GP model procedure. In this procedure GP is used to analyze the output of AHP and Leopold matrix which have most closely met the DMs' goals.

\section{Results}

\subsection{AHP application}

In this part, AHP method is applied for weighting the water reuse alternatives in Najafabad region. At first, subjective judgments are obtained from questionnaires and the importance of the various criteria and alternatives are separately evaluated by three decision-makers and represented in the formats of the numerical values (see Table 6) and the proposed algorithm that assesses the criteria weights and builds the pairwise comparisons for the five criteria and three water reuse alternatives relevant to each attribute.

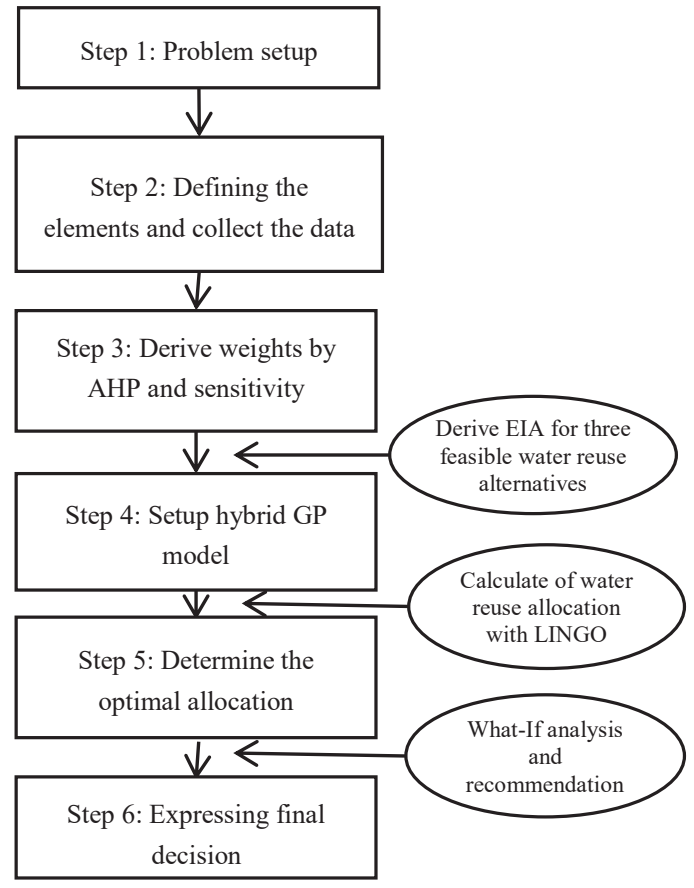

Fig. 5 Hybrid model development procedure

Table 7 indicates some important criteria that have been utilized in the literatures [39]. In the first step, according to Table 6 , the five criteria including $E_{1}$ : Environmental criteria, $E_{2}$ : Risk-based criteria, $E_{3}$ : Economic criteria, $E_{4}$ : Social criteria, and $E_{5}$ : Functional criteria, were selected. Then the questionnaires were asked to evaluate the importance of each criterion.

Table 7 Evaluation criteria utilized in literature of water supply and demand management options

\begin{tabular}{|c|c|}
\hline $\begin{array}{l}\text { Evaluation Criteria } \\
\text { (abbreviation) }\end{array}$ & \\
\hline \multirow{3}{*}{$\begin{array}{l}\text { Environmental } \\
\text { criteria }\left(E_{1}\right)\end{array}$} & Maintain river, local creaks, and wetlands \\
\hline & Efficient resource use \\
\hline & Protect land ecosystem \\
\hline \multirow{2}{*}{$\begin{array}{l}\text { Risk-based criteria } \\
\left(E_{2}\right)\end{array}$} & Resilience \\
\hline & Vulnerability \\
\hline \multirow{2}{*}{$\begin{array}{l}\text { Economic criteria } \\
\left(E_{3}\right)\end{array}$} & Cost \\
\hline & Income \\
\hline
\end{tabular}

Ability to meet user acceptance

Ability to meet community acceptance

Social criteria $\left(E_{4}\right)$

$$
\begin{aligned}
& \text { Health and hygiene } \\
& \text { Political approval }
\end{aligned}
$$

Optional, operational, maintenance and construction

Functional criteria $\left(E_{5}\right)$

$$
\text { flexibility }
$$

Objectives

\section{Effects on aquifer (groundwater level and pattern) \\ Reuse and recycling of resources \\ Effects on natural habitat area}

Failure duration or how quickly system returns to its satisfactory state after a failure

Magnitude of failure

Capital, maintenance and operational cost

Products income

Water quality acceptance by user

Creates jobs, benefits and negative impacts on local area public education

Safety, Risk of infections

Ability to meet environmental or other regulations and management effectiveness

Ease of handling the system
Infrastructure design life and effects on the environment and facilities 
Then, based on Eqs. (1) and (2), the pairwise decision matrix is normalized and relative weights of the attributes and alternatives are determined by using the Saaty matrix [40]. After the criterion weights, the decision and measurement of normalized matrix are summarized and shown in Tables 8 and 9.

\section{Normalized criteria aggregation}

Consequently, following this process, weights of the alternatives are determined Eq. (14):

$$
\begin{aligned}
& R\left(T_{1}\right)=\left(\begin{array}{l}
r\left(T_{1} E_{1}\right) \times r\left(E_{1}\right)+r\left(T_{1} E_{2}\right) \times r\left(E_{2}\right) \\
+r\left(T_{1} E_{3}\right) \times r\left(E_{3}\right)+r\left(T_{1} E_{4}\right) \times r\left(E_{4}\right) \\
+r\left(T_{1} E_{5}\right) \times r\left(E_{5}\right)+r\left(T_{1} E_{6}\right) \times r\left(E_{6}\right)
\end{array}\right) \\
& =0.2547 ; R\left(T_{2}\right)=0.5547 \text { and } R\left(T_{3}\right)=0.1907 .
\end{aligned}
$$

The final weights according to normalized criteria aggregation are presented in Table 10.

\subsubsection{Sensitivity analysis application}

In this case study the weight of the environmental and social attributes are important issues in facing of environmental protection and social crisis and the strategy to increase or decrease of these attribute weights provides information on the solution stability and also resulting of change in the water reuse allocation can be studied.

Table 8 Pairwise comparison matrix and relative importance weights of the attributes in AHP method

\begin{tabular}{lcccccc}
\hline Criteria & $E_{1}$ & $E_{2}$ & $E_{3}$ & $E_{4}$ & $E_{5}$ & $\begin{array}{c}\text { Weights } \\
(\mathrm{Wk})\end{array}$ \\
\hline$E_{1}$ & 1 & 4 & 5 & $1 / 4$ & 6 & 0.288 \\
$E_{2}$ & $1 / 4$ & 1 & 2 & $1 / 3$ & 3 & 0.120 \\
$E_{3}$ & $1 / 5$ & $1 / 2$ & 1 & $1 / 4$ & 2 & 0.076 \\
$E_{4}$ & 4 & 3 & 4 & 1 & 5 & 0.467 \\
$E_{5}$ & $1 / 6$ & $1 / 3$ & $1 / 2$ & $1 / 5$ & 1 & 0.050 \\
$\lambda_{\max }=5.413, C I=0.103$ & $R I=1.1086 ;$ and $C R=0.093 \leq 0.1$ & Sum: 1.000 \\
\hline
\end{tabular}

Table 9 Weight vectors of the criterions and alternatives for weighting water reuse in AHP method

\begin{tabular}{lccccc}
\hline$r\left(T_{i} E_{j}\right)$ & $E_{1}$ & $E_{2}$ & $E_{3}$ & $E_{4}$ & $E_{5}$ \\
\hline$T_{1}$ & 0.589 & 0.055 & 0.149 & 0.122 & 0.207 \\
$T_{2}$ & 0.357 & 0.290 & 0.066 & 0.804 & 0.735 \\
$T_{3}$ & 0.054 & 0.655 & 0.785 & 0.074 & 0.058 \\
\hline
\end{tabular}

Table 10 The final priorities and weights of the alternatives in AHP method

\begin{tabular}{lcc}
\hline Ranking & Alternatives & Weight $R\left(T_{i}\right)$ \\
\hline 2 & $T_{1}$ & $\mathbf{0 . 2 5 4 7}$ \\
1 & $T_{2}$ & $\mathbf{0 . 5 5 4 7}$ \\
3 & $T_{3}$ & $\mathbf{0 . 1 9 0 7}$ \\
\hline
\end{tabular}

Suppose that we first interest in varying the weight of the environmental attribute $E_{1}$, Eq. (5) is shown which the sum of all attribute weights is one.

Based on Eq. (8), the weights of attributes calculated $\left(E_{2}=0.120, E_{3}=0.076, E_{4}=0.467, E_{5}=0.05\right)$, and based on sensitivity analysis section $p_{1}-p_{5}$ values are as follows: $p_{1}=1.579, p_{2}=6.145$, and $p_{3}=0.65$

When the weight of environmental or social attribute is varied from 0 to 1 , the value of the other attributes are recalculated. If the weight social criterion is changed the similar procedure is valid. Table 11 shown the new weights of water reuse allocation attributes and alternatives in 5 models when the weight of environmental or social attributes is decreased or increased.

\subsection{Leopold matrix application}

The input numbers in the Leopold matrix not only identify the environmental areas affected by each project activity, but also work as a scale of the effect's level. Table 12 provides an illustration of the basic structure of EIA matrix for the urban landscape irrigation, and Table 13 summarizes EIA matrix for three feasible water reuse alternatives based on the UN SDGs $\left(G_{1}\right.$ : No Poverty, $G_{2}$ : Zero Hunger, $G_{3}$ : Good

\begin{tabular}{|c|c|c|c|c|c|}
\hline Model & 1 & 2 & 3 & 4 & 5 \\
\hline Varying environmental or social attribute weights & $1 * E_{1}$ and $1 * E_{4}$ & $0.25 * E_{1}$ & $1.25 * E_{1}$ & $0.25 * E_{4}$ & $1.25 * E_{4}$ \\
\hline$W_{E 1}$ & 0.288 & 0.072 & 0.360 & 0.476 & 0.224 \\
\hline$W_{E 2}$ & 0.120 & 0.156 & 0.108 & 0.198 & 0.094 \\
\hline$W_{E 3}$ & 0.076 & 0.099 & 0.068 & 0.126 & 0.059 \\
\hline$W_{E 4}$ & 0.467 & 0.608 & 0.419 & 0.117 & 0.584 \\
\hline$W_{E 5}$ & 0.050 & 0.065 & 0.045 & 0.083 & 0.039 \\
\hline$W_{T 1}$ & 0.2547 & 0.1532 & 0.2885 & 0.3416 & 0.2254 \\
\hline$W_{T 2}$ & 0.5547 & 0.6142 & 0.5344 & 0.3905 & 0.6093 \\
\hline$W_{T 3}$ & 0.1907 & 0.2326 & 0.1772 & 0.2680 & 0.1653 \\
\hline
\end{tabular}

Table 11 The new weights of attributes and alternatives in water reuse project, in 5 models 
Table 12 EIA matrix for "urban landscape irrigation"

\begin{tabular}{|c|c|c|c|c|c|c|c|c|c|c|c|c|c|c|c|c|c|c|c|c|}
\hline \multicolumn{21}{|c|}{ Project Activities } \\
\hline \multicolumn{9}{|c|}{ Construction phase } & \multicolumn{12}{|c|}{ Operation phase } \\
\hline 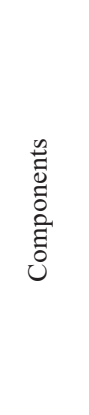 & 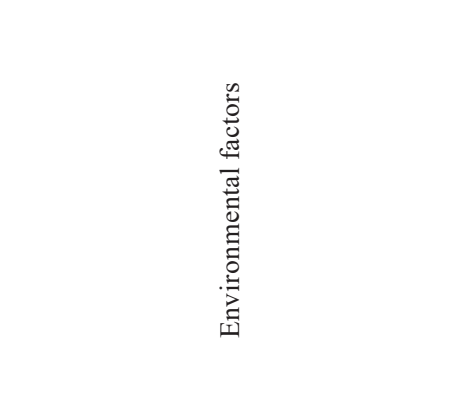 & 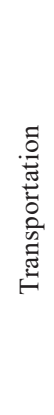 & 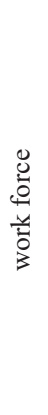 & 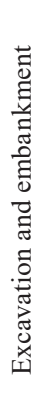 & 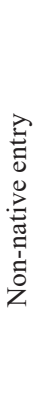 & 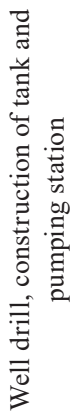 & 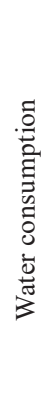 & 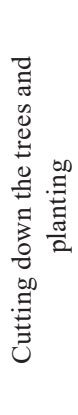 & 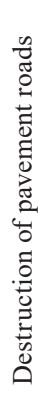 & 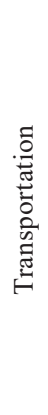 & 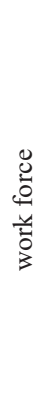 & 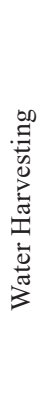 & 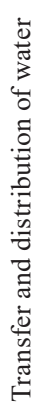 & 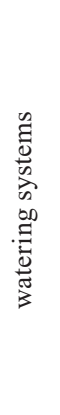 & 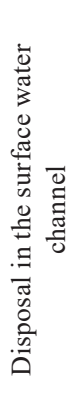 & 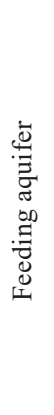 & 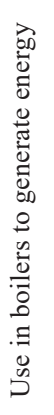 & 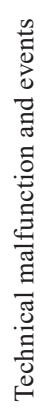 & 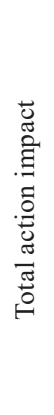 & 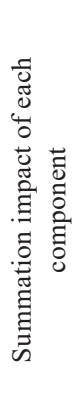 \\
\hline \multirow{8}{*}{ 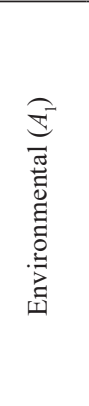 } & Soil erosion $\left(G_{15}\right)$ & 0 & 0 & -1 & 0 & 0 & 0 & 0 & 0 & 0 & 0 & 0 & 0 & 4 & 0 & 0 & 0 & 0 & 3 & \multirow{8}{*}{28} \\
\hline & Soil quality $\left(G_{15}\right)$ & 0 & 0 & 0 & 0 & 0 & 0 & 0 & 0 & 0 & 0 & 0 & 0 & 6 & 0 & 0 & 0 & 0 & 6 & \\
\hline & Air quality $\left(G_{15}\right)$ & -1 & 0 & -1 & 0 & 0 & 0 & 0 & 0 & 0 & 0 & 0 & 0 & 0 & 0 & 0 & 0 & 0 & -2 & \\
\hline & Noise $\left(G_{15}\right)$ & -1 & 0 & -1 & 0 & 0 & 0 & 0 & 0 & 0 & 0 & 0 & 0 & 0 & 0 & 0 & 0 & 0 & -2 & \\
\hline & Vegetation $\left(G_{15}\right)$ & 0 & 0 & 0 & 0 & 0 & 0 & -1 & 0 & 0 & 0 & 0 & 0 & 6 & 0 & 0 & 0 & 0 & 5 & \\
\hline & wild life $\left(G_{15}\right)$ & -1 & 0 & -1 & 0 & 0 & 0 & -1 & 0 & 0 & 0 & 0 & 0 & 0 & 0 & 0 & 0 & 0 & -3 & \\
\hline & Water quality $\left(G_{6}, G_{12}, G_{13}\right)$ & 0 & 0 & 0 & 0 & 0 & 0 & 0 & 0 & 0 & 0 & 0 & 0 & 6 & 0 & 0 & 0 & 0 & 6 & \\
\hline & $\begin{array}{l}\text { Quantity of water resources } \\
\qquad\left(G_{6}, G_{10}, G_{12}, G_{13}\right)\end{array}$ & 0 & 0 & 0 & 0 & 0 & -1 & 0 & 0 & 0 & 0 & 15 & 0 & 0 & 1 & 0 & 0 & 0 & 15 & \\
\hline \multirow{2}{*}{ 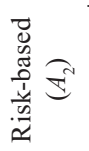 } & Mental health and health $\left(G_{3}\right)$ & 0 & 0 & 0 & 0 & 0 & 0 & 0 & 0 & 0 & 0 & 0 & 0 & -4 & 0 & 0 & 0 & -2 & -6 & \multirow{2}{*}{-18} \\
\hline & Physical health and health $\left(G_{3}\right)$ & 0 & 0 & 0 & 0 & 0 & 0 & 0 & 0 & 0 & 0 & 0 & 0 & -6 & -2 & 0 & 0 & -4 & -12 & \\
\hline \multirow{2}{*}{ 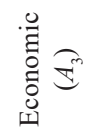 } & Financial $\left(G_{8}\right)$ & 0 & 0 & 0 & 1 & 0 & 0 & 0 & 0 & 0 & 0 & 0 & 0 & 0 & 0 & 0 & 0 & 0 & 1 & \multirow[b]{2}{*}{4} \\
\hline & $\begin{array}{l}\text { Employment and unemployment } \\
\qquad\left(G_{1}, G_{2}\right)\end{array}$ & 0 & 2 & 0 & 0 & 0 & 0 & 0 & 0 & 0 & 1 & 0 & 0 & 0 & 0 & 0 & 0 & 0 & 3 & \\
\hline \multirow{5}{*}{$\begin{array}{l}\mathbb{J}^{7} \\
\frac{\pi}{0} \\
0 \\
0 \\
\text { is }\end{array}$} & Recreation and tourism $\left(G_{16}\right)$ & 0 & 0 & 0 & 0 & 0 & 0 & 0 & 0 & 0 & 0 & 0 & 0 & -4 & 0 & 0 & 0 & 0 & -4 & \multirow{5}{*}{-2} \\
\hline & Landscapes $\left(G_{15}\right)$ & 0 & 0 & 0 & 0 & 0 & 0 & -1 & -1 & 0 & 0 & 0 & 0 & 4 & 0 & 0 & 0 & 0 & 2 & \\
\hline & $\begin{array}{l}\text { Education and cultural situation } \\
\qquad\left(G_{4}, G_{17}\right)\end{array}$ & 0 & 0 & 0 & -1 & 0 & 0 & 0 & 0 & 0 & 0 & 0 & 0 & 0 & 0 & 0 & 0 & 0 & -1 & \\
\hline & Land use $\left(G_{15}\right)$ & 0 & 0 & 0 & 0 & 0 & 0 & 0 & 0 & 0 & 0 & 0 & 0 & 1 & 0 & 0 & 0 & 0 & 1 & \\
\hline & The value of land and housing $\left(G_{11}\right)$ & 0 & 0 & 0 & 0 & 0 & 0 & 0 & 0 & 0 & 0 & 0 & 0 & 0 & 0 & 0 & 0 & 0 & 0 & \\
\hline 过 & Distance from production site $\left(G_{9}, G_{11}\right)$ & 1 & 0 & 0 & 0 & 0 & 0 & 0 & 0 & 1 & 0 & 0 & 0 & 0 & 0 & 0 & 0 & 0 & 2 & 2 \\
\hline \multicolumn{2}{|c|}{ Summation of Total Impact Factor } & -2 & 2 & -4 & $\mathbf{0}$ & $\mathbf{0}$ & -1 & -3 & -1 & 1 & 1 & 15 & $\mathbf{0}$ & 13 & -1 & $\mathbf{0}$ & $\mathbf{0}$ & -6 & 14 & 14 \\
\hline
\end{tabular}

A negative sign (-) in the front of the number shows that the impact is adverse and $\left(G_{n}\right)$ sign, following the sustainability criteria indicates the number of UN Sustainable Development Goals (SDGs) in the EIA. The weights of water reuse allocation attributes based on Table 11 is used to weight the "summation impact of each component" in the objective function of GP models.

Health and Well-being, $G_{4}$ : Quality Education, $G_{5}$ : Gender Equality, $G_{6}$ : Clean Water and Sanitation, $G_{7}$ : Affordable and Clean Energy, $G_{8}$ : Decent Work and Economic Growth, $G_{9}$ : Industry, Innovation and Infrastructure, $G_{10}$ : Reduced Inequality, $G_{11}$ : Sustainable Cities and Communities, $G_{12}$ : Responsible Consumption and Production, $G_{13}$ : Climate Action, $G_{14}$ : Life Below Water, $G_{15}:$ Life on Land, $G_{16}$ : Peace and Justice Strong Institutions and $G_{17}$ : Partnerships to achieve the Goal). These matrixes which has existing environmental items, which might be impacted by proposed project activity are identified as the rows and actions, which cause environmental impacts, as the columns of the matrix.

Each cell in the EIA matrix of water reuse alternatives indicates net privilege for impact and obtained of multiplying the magnitude by the significance of the effect. In this method, + or - sign of the effects indicate the positive or negative impact of each environmental component and the degree of impact indicates magnitude of the impact. 
Table 13 EIA matrix for "the three feasible water reuse alternatives"

\begin{tabular}{|c|c|c|c|c|c|c|c|c|c|c|c|}
\hline \multirow[b]{2}{*}{ Components } & \multirow{2}{*}{$\begin{array}{l}\text { Three feasible alternatives } \\
\text { Environmental factors }\end{array}$} & \multicolumn{3}{|c|}{$\begin{array}{l}\text { Urban landscape } \\
\text { irrigation }\left(T_{1}\right)\end{array}$} & \multicolumn{3}{|c|}{$\begin{array}{l}\text { Agricultural } \\
\text { irrigation }\left(T_{2}\right)\end{array}$} & \multicolumn{3}{|c|}{$\begin{array}{l}\text { Industrial demand } \\
\qquad\left(T_{3}\right)\end{array}$} & \multirow{2}{*}{ 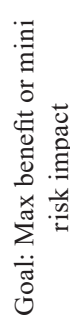 } \\
\hline & & 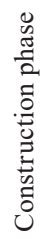 & 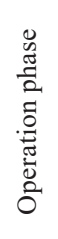 & 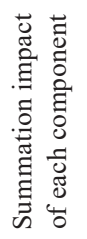 & 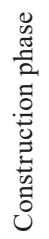 & 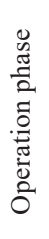 & 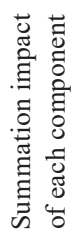 & 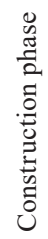 & 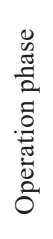 & 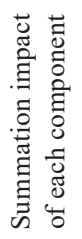 & \\
\hline \multirow{8}{*}{ Environmental $\left(A_{1}\right)$} & Soil erosion $\left(G_{15}\right)$ & -1 & 4 & 28 & -2 & 4 & 20 & -2 & 0 & -11 & \multirow{8}{*}{28} \\
\hline & Soil quality $\left(G_{15}\right)$ & 0 & 6 & & 0 & 9 & & 0 & 0 & & \\
\hline & Air quality $\left(G_{15}\right)$ & -2 & 0 & & -2 & 0 & & -2 & 0 & & \\
\hline & Noise $\left(G_{15}\right)$ & -2 & 0 & & -2 & 0 & & -2 & 0 & & \\
\hline & Vegetation $\left(G_{15}\right)$ & -1 & 6 & & -1 & 0 & & 0 & 0 & & \\
\hline & wild life $\left(G_{15}\right)$ & -3 & 0 & & -3 & 0 & & -4 & 0 & & \\
\hline & Water quality $\left(G_{6}, G_{12}, G_{13}\right)$ & 0 & 6 & & -1 & 12 & & 0 & 0 & & \\
\hline & Quantity of water resources $\left(G_{6}, G_{10}, G_{12}, G_{13}\right)$ & -1 & 16 & & 0 & 6 & & -1 & 0 & & \\
\hline \multirow{2}{*}{$\begin{array}{l}\text { Risk-based } \\
\left(A_{2}\right)\end{array}$} & Mental health and health $\left(G_{3}\right)$ & 0 & -6 & -18 & 0 & 0 & -6 & 0 & -1 & -2 & \multirow{2}{*}{-2} \\
\hline & Physical health and health $\left(G_{3}\right)$ & 0 & -12 & & 0 & -6 & & 0 & -1 & & \\
\hline \multirow{2}{*}{$\begin{array}{l}\text { Economic } \\
\left(A_{3}\right)\end{array}$} & Financial $\left(G_{8}\right)$ & 1 & 0 & 4 & 1 & 0 & 3 & 0 & 9 & 14 & \multirow{2}{*}{14} \\
\hline & Employment and unemployment $\left(G_{1}, G_{2}\right)$ & 2 & 1 & & 1 & 1 & & 1 & 4 & & \\
\hline \multirow{5}{*}{ Social $\left(A_{4}\right)$} & Recreation and tourism $\left(G_{16}\right)$ & 0 & -4 & -2 & 0 & 0 & 6 & 0 & 0 & -3 & \multirow{5}{*}{6} \\
\hline & Landscapes $\left(G_{15}\right)$ & -2 & 4 & & -1 & 4 & & -2 & 0 & & \\
\hline & Education and cultural situation $\left(G_{4}, G_{17}\right)$ & -1 & 0 & & -1 & 0 & & -1 & 0 & & \\
\hline & Land use (G15) & 0 & 1 & & 0 & 4 & & 0 & 0 & & \\
\hline & The value of land and housing (G11) & 0 & 0 & & 0 & 0 & & 0 & 0 & & \\
\hline Functional $\left(A_{5}\right)$ & Distance from production site $(G 9, G 11)$ & 1 & 1 & 2 & 2 & 2 & 4 & 1 & 0 & 1 & 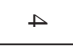 \\
\hline Total Factor Impact & -9 & 23 & 14 & -9 & 36 & 27 & -12 & 11 & -1 & & \\
\hline
\end{tabular}

The maximum benefit or minimum risk impact value among the three feasible water reuse alternatives in each row indicate the best EIA condition for water reuse allocation when only considering that goal. In other words, by considering the environmental components, with regards to allocation water reuse for all of the alternatives, the maximum impact value with score of 28 with water reuse demand $120 \mathrm{l} / \mathrm{s}$ for urban landscape irrigation is the best condition, while according to the effect on the economic components, the maximum impact with score of 14 with water reuse demand $260 \mathrm{l} / \mathrm{s}$ for agricultural irrigation is the best condition. These aggregate scores are converted into the constraint values in GP model, which will attempt to consider the best EIA condition by minimizing the deviation from the ideal score for each group.

\subsection{Application of GP and proposed framework for water reuse allocation}

In the study area, we considered the Leopold matrix in order to carrying-out the EIA for water reuse allocation by formulating of AHP-GP models as below:

\subsubsection{Constraint functions}

First, we determine the following functions as constraints:

$T_{1}+T_{2}+T_{3} \leq 420$.

Equation (15) shows the maximum volume (1/s) of water reuse production capacity. Where $T_{1}, T_{2}$ and $T_{3}$ : are water reuse allocation volume $(1 / \mathrm{s})$ of feasible water reuse alternatives include: agricultural irrigation, urban landscape irrigation and industrial demand.

$T_{1} \geq 120 ; T_{2} \geq 260$ and $T_{3} \geq 150$.

Equation (16) is minimum feasible volume of water reuse allocation for $T_{1}, T_{2}$ and $T_{3}$. They should be equal or more than 120, 260 and $150 \mathrm{l} / \mathrm{s}$ respectively, that are determined based on the future demand.

In GP model, Leopold matrix is used for finding the best relative weighting $\left(A_{i j}\right)$ of decision variables to support the constraint coefficients due to carrying-out the EIA for water reuse allocation for each constraints (goals) and Eq. (17) to Eq. (21) are presented the goals for this project: 
$\operatorname{Max} \sum_{i=1}^{m} A_{i j} * T_{i}:$ Maximization or minimization of all

criteria per $\frac{l}{s}$ of water reuse allocation

$28 * T_{1}+20 * T_{2}-11 * T_{3} \geq 28$.

Equation (17) is minimum feasible water reuse alternatives impacts caused by project activities to environmental component and the coefficients for decision variables $\left(T_{1}\right.$ to $T_{3}$ ) are the sequestrated of environmental effects for each alternative based on results of EIA matrix in Table 13. The maximum value of multiply impact assessment per $1 / \mathrm{s}$, in water reuse demand for each alternative represents the best condition when only considering that attribute. In other words, with regards to environmental impact assessment, alternative $T_{1}$ is the maximum value with a score of 28 .

$-18 * T_{1}-6^{*} T_{2}-2 * T_{3} \leq-2$.

Equation (18) is maximum feasible water reuse alternatives impacts caused of project activities to risk-based component and the coefficients for decision variables ( $T_{1}$ to $T_{3}$ ) are the sequestrated of health risks effects for each alternative based on results of EIA matrix in Table 13.

$4^{*} T_{1}+3^{*} T_{2}+14 * T_{3} \geq 14$.

Equation (19) is minimum feasible water reuse alternatives impacts caused by project activities to economic component and the coefficients for decision variables ( $T_{1}$ to $T_{3}$ ) are the sequestrated of economic factors effects for each alternative based on the results of EIA matrix in Table 13.

$-2 * T_{1}+6^{*} T_{2}-3^{*} T_{3} \geq 6$.

Equation (20) is minimum feasible water reuse alternatives impacts caused by project activities to social and the coefficients for decision variables ( $T_{1}$ to $\left.T_{3}\right)$ are the sequestrated public acceptance effects for each alternative based on the results of EIA matrix in Table 13.

$2^{*} T_{1}+4 * T_{2}+T_{3} \geq 4$.

Equation (21) is minimum feasible water reuse alternatives impacts caused by project activities to functional component and the coefficients for decision variables $\left(T_{1}\right.$ to $\left.T_{3}\right)$ are the sequestrated of simple application effects for each alternative based on the results of EIA matrix in Table 13.

We determined the negative or positive deviation of the goal based on the constraints specification. If the initial constraint or inequality is greater than a quantity, negative deviation must be included in the equation. This negative deviation should be written to the left-hand side of the equation and inequality will be changed to equality. If the initial limitation is less than a quantity, the positive deviation must be subtracted from the left-hand side of the equation.

On the other hand, the signs $D_{i}^{-}$or $D_{i}^{+}$symbols can be added to the relationships 16 to 21 in the various mentioned cases. Given the properties of the constraints of this study, we only have a positive deviation from the target of health hazards. As a result, the following new equations are determined:

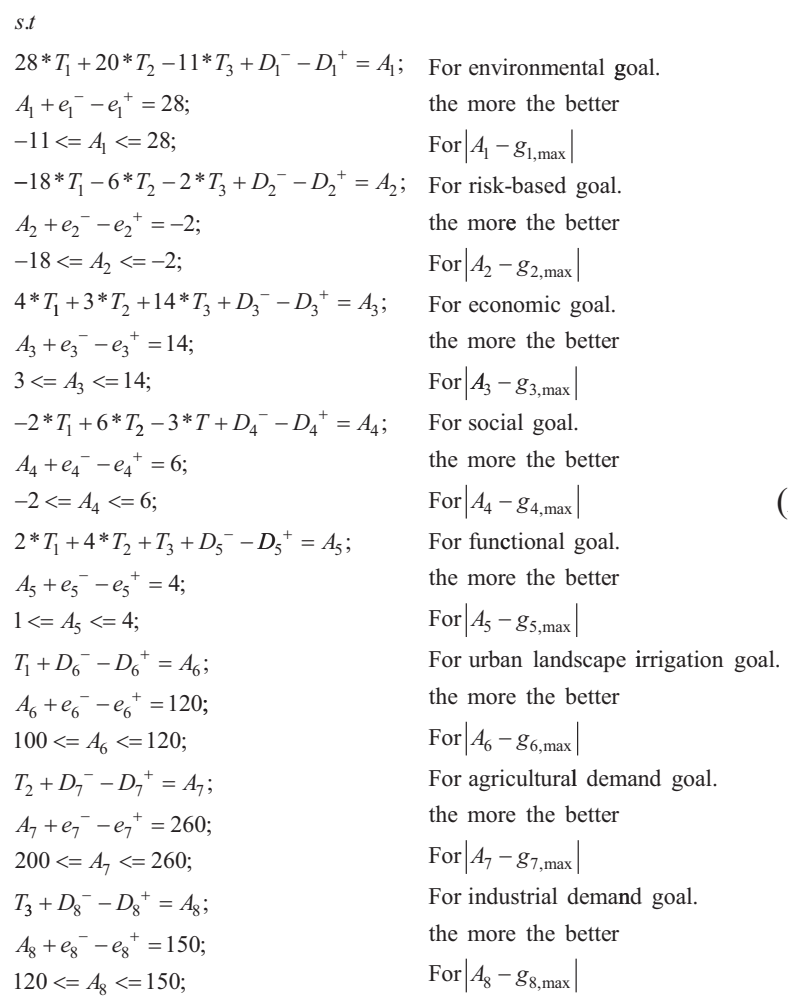

where, $D_{1}^{-}$and $e_{1}^{-}$are negative deviation of environmental impact assessment, $D_{2}^{-}$and $e_{2}^{-}$are negative deviation of risk-based impact assessment, $D_{3}^{-}$and $e_{3}^{-}$are negative deviation of economic impact assessment, $D_{4}^{-}$and $e_{4}^{-}$are negative deviation of social impact assessment, $D_{5}^{+}$and $e_{5}{ }^{-}$are negative deviation of functional impact assessment, $D_{6}{ }^{-}$and $e_{6}^{-}$are negative deviation of urban landscape irrigation allocation, $D_{7}^{-}$and $e_{7}^{-}$are negative deviation of agricultural irrigation allocation, $D_{8}^{-}$and $e_{8}^{-}$are negative deviation of industrial demand allocation.

\subsubsection{Objective functions}

In the GP method, simplifying the objective function not only make selecting weight easy, but also make working with relative deviations of goals simpler. Therefore, using 
mathematical techniques and changing weight factors and creating different solutions can help decision makers choose the optimal solution to fulfil the objectives of the EIA process. To indicate the relative importance of each objective based on the weighting value which evaluated by expert's judgment for each alternatives and criteria, we can combine these weighting with GP model and attempt to achieve the best recycling water allocation.

The unfavorable deviation from the goals was minimized by objective function. We determined the objective functions as below:

$\begin{array}{ll}\text { Objective functions of AHP-GP formulation: for model } 1 \text { to } 5 \\ \operatorname{minz}=\left(W_{E 1} / 28\right)^{*}\left(? D_{1}^{-}+e_{1}^{-}\right)+ & \text {Satisfy environmental goal } \\ \left(W_{E 2} / 2\right) *\left(D_{2}^{-}+e_{2}^{-}\right)+ & \text {Satisfy risk-based goal } \\ \left(W_{E 3} / 14\right) *\left(D_{3}^{-}+e_{3}^{-}\right)+ & \text {Satisfy economic goal } \\ \left(W_{E 4} / 6\right) *\left(D_{4}^{-}+e_{4}^{-}\right)+ & \text {Satisfy social goal } \\ \left(W_{E 5} / 4\right) *\left(D_{5}^{+}+e_{5}^{+}\right)+ & \text {Satisfy functional goal } \\ \left(W_{T 1} / 120\right) *\left(D_{6}^{-}+e_{6}^{-}\right)+ & \text {Satisfy landscape irrigation goal } \\ \left(W_{T 2} / 260\right) *\left(D_{7}^{-}+e_{7}^{-}\right)+ & \text {Satisfy agricultural irrigation goal } \\ \left(W_{T 3} / 150\right) *\left(D_{8}^{-}+e_{8}^{-}\right) ; & \text {Satisfy industrial demand goal }\end{array}$

Equation (23) is the objective function that generates an optimal solution based on the deviational variable that represents each goal. In the study area, AHP method is used for finding the best relative weighting of criterion $\left(E_{i}\right)$ and alternatives $\left(T_{i}\right)$ to support the coefficients of underachievement deviations $\left(D_{i}^{-}\right.$and $\left.e_{i}^{-}\right)$in the objective function of GP formulating in AHP-GP models.

\subsubsection{Water reuse allocation based on sensitivity analysis models}

The weights of criteria and alternatives obtained by AHP method and also sensitivity analysis procedure of this method is shown in Table 11. As can be seen in Table 11, the weights are normalized, so the AHP technique can be combined with multi objective optimization techniques such as goal programming. Performance sensitivity analysis in proposed framework shows how recycle water are allocated relative to water reuse alternatives with respect to vary of each attribute as well as overall.

Table 14 The final output for water reuse allocation per $1 / \mathrm{s}$, by alternatives in 5 models

\begin{tabular}{lccccc}
\hline \multirow{5}{*}{ Model } & 1 & 2 & 3 & 4 & 5 \\
& & $0.25 * E_{1}$ & $1.25 * E_{1}$ & $0.25 * E_{4}$ & $1.25 * E_{4}$ \\
\hline$\left(T_{1}\right)$ & 120 & 10 & 120 & 120 & 120 \\
$\left(T_{2}\right)$ & 260 & 260 & 260 & 150 & 260 \\
$\left(T_{3}\right)$ & 40 & 150 & 40 & 150 & 40 \\
\hline
\end{tabular}

The advantage of this approach is the ability to allow the DMs to change of attributes and alternative weights and notice the correlating change of water reuse allocation.

Finally, multiple problems based on objective and constraint functions were defined as mathematical linear based on sensitivity analysis in 5 models solved by LINGO software. The final output for water reuse allocation per $1 / \mathrm{s}$, are presented as follows (Table 14). In pervious section the What-If analysis is performed in 5 AHP-GP models based on sensitivity analysis of AHP method then recycle water allocation are calculated which can be provided information on the worthy and stability of the solution in decision-making.

The advantage of this approach is the ability to allow the DMs to change of attributes and alternative weights and notice the correlating change of water reuse allocation.

\subsubsection{Recommendation for a case study related to the sensitivity analysis and corresponding results}

In relation to the mathematical computations, it is clear that DMs cannot do all the above calculations and some flexible model is required to handle them simultaneously. Another ability of this approach is the strength to create "What-If" analysis. Therefore, when management wants to consider change in weighting of problem, this model can be used to answer the "If" state. This function is useful for managing water reuse allocation because we can see how different attribute weights effect on the amount of water reuse allocation. In this section, results of changes in the attribute weights in water reuse project and the impact of this change on the water reuse allocation in pervious section (Tables 11 and 14) are compared and discussed as follows:

The change of the environmental attribute $\left(E_{1}\right)$ weight that changes the existing the allocation of recycled water is 0.072 , and this causes the allocation of urban landscape irrigation $\left(T_{1}\right)$ decries from 120 to $10 \mathrm{l} / \mathrm{s}$ and the allocation of industrial demand increase from 40 to $150 \mathrm{l} / \mathrm{s}$. Because -75 $\%$ changes in environmental weight results (decrease in the environmental weight from 0.288 to 0.072 ), in allocation of recycled water decries, it could be recommended to the DMs to allocate $120 \mathrm{l} / \mathrm{s}$ for urban landscape irrigation, because change in allocation of recycled water for this alternative need to a great change in environmental criteria weight.

Change in weight of the social attribute (E4) shows that, depending on the value of this attribute weight and water reuse allocation, results of model 1 can be considered as the optimal allocation for alternatives $T_{1}$ to $T_{3}$. It is also shown that allocation for industrial demand $\left(T_{3}\right)$ increase if the weight of the social attribute is decreased considerably 
- at least for 0.117 , which is a great change on scale of 0 to 1. If such a situation occurs, this would mean that the DMs did not take into account the impact of the solution to be implemented on the social, and consequently, that the decision should be reassessed to be in compliance with the globally accepted recommendations regarding sustainability.

\section{Conclusions}

This study introduces the summary of using AHP, Leopold matrix and GP methods, for optimizing water reuse allocation based on proposed framework approach to support the decision-making for water reuse allocation in the presence of conflicting attributes. The significant attributes include: economic, functional, social, risk-based and environmental criteria in a region with water-stress and arid climate.

This is also the first study that considers the Leopold matrix for carrying-out the EIA, based on maximizing positive effects and minimizing the negative effects of project performance. Therefore, a new concept of optimal theory and an innovative paradigm shift towards more sustainable management in water reuse allocation can be designed, which regional control strategies for several goals are included.

Water reuse allocation is an inherently multidimensional process. In this paper the proposed framework approach gives a better tool which attempts to argue for water reuse

\section{References}

[1] Hranova, R. "Application of a system approach and optimisation of different alternatives in the practice of decentralised wastewater reuse", Civil Engineering and Environmental System, 27(4), pp. 281-294, 2010.

https://doi.org/10.1080/10286600902883173

[2] Sharma, S., Balan, S. "An integrative supplier selection model using Taguchi loss function, TOPSIS and multi criteria goal programming", Journal of Intelligent Manufacturing, 24(6), pp. 1123-1130, 2013. https://doi.org/10.1007/s10845-012-0640-y

[3] Aznar, J., Guijarro, F., Moreno-Jiménez, J. M. "Mixed valuation methods: a combined AHP-GP procedure for individual and group multicriteria agricultural valuation", Annals of Operations Research, 190(1), pp. 221-238, 2011.

https://oi.org/10.1007/s10479-009-0527-2

[4] Ostadhashemi, R., Rostami Shahraji, T., Mohammadi Limaei, S., Roehle, H. "Goal programming and analytical hierarchy process approaches for sustainable plantation", Caspian Journal of Environmental Sciences, 12(2), pp. 233-244, 2014. [online] Available at: https://cjes.guilan.ac.ir/article_1151.html [Accessed: 22 February 2020]

[5] Wallenius, J., Dyer, J. S., Fishburn, P. C., Steuer, R. E., Zionts, S., Deb, K. "Multiple Criteria Decision Making, Multiattribute Utility Theory: Recent Accomplishments and What Lies Ahead", Management Science, 54(7), pp. 1336-1349, 2008. https://doi.org/10.1287/mnsc.1070.0838 allocation. AHP and Leopold matrix uses for translating expert reports into priorities and using weightings to generate GP method goals has proved to be a valuable aid in helping DMs to ensure impartiality and consistency in the water reuse allocation. The proposed model aims to optimize the water reuse allocation while taking in mind the financial considerations of water reuse as well as other targets. The results indicate that the combination of quantitative evaluation, optimization and mathematical modelling can be considered as an effective tool for creating better guidelines for alternatives composition, profitability and allocation of resources than current management.

Finally, in this study, we can simultaneously manage several purposes direction and determine the appropriate water reuse allocation and notice the correlating change of water reuse allocation based on sensitivity analysis, which is capable to determine intervals where the water reuse allocation is sensitive to the change of attribute or alternative weights and how the changes in these weights influence on the water reuse allocation.

\section{Acknowledgement}

The authors wish to express their special thanks to the anonymous reviewers who have given vital input for improving the quality of the manuscript.

[6] Scott, J. A., Ho, W., Dey, P. K. "A review of multi-criteria decision-making methods for bioenergy systems", Energy, 42(1), pp. 146-156, 2012. https://doi.org/10.1016/j.energy.2012.03.074

[7] Tzeng, G.-H., Huang, J.-J. "Multiple Attribute Decision Making, Methods and Applications", 1st ed., CRC Press, Boca Raton, FL, USA, 2011.

https://doi.org/10.1201/b11032

[8] Cheng, C.-H., Yang, K.-L., Hwang, C.-L. "Evaluating attack helicopters by AHP based on linguistic variable weight", European Journal of Operational Research, 116(2), pp. 423-435, 1999. https://doi.org/10.1016/S0377-2217(98)00156-8

[9] Srdjevic, Z., Samardzic, M., Srdjevic, B. "Robustness of AHP in selecting wastewater treatment method for the coloured metal industry: Serbian case study", Civil Engineering and Environmental Systems, 29(2), pp. 147-161, 2012. https://doi.org/10.1080/10286608.2012.672412

[10] Tamiz, M., Jones, D., Romero, C. "Goal programming for decision making: An overview of the current state-of-the-art", European Journal of Operational Research, 111(3), pp. 569-581, 1998. https://doi.org/10.1016/S0377-2217(97)00317-2

[11] Jones, D., Tamiz, M. "Practical Goal Programming", 1st ed., Springer, Boston, MA, USA, 2010. https://doi.org/10.1007/978-1-4419-5771-9 
[12] Charnes, A., Cooper, W. W. "Management Models and Industrial Applications of Linear Programming", Management Science, 4(1), pp. 1-113, 1957. https://doi.org/10.1287/mnsc.4.1.38

[13] Kangas, A., Kangas, J., Kurttila, M. "Decision Support for Forest Management", 1st ed., Springer, Dordrecht, Netherlands, 2008. https://doi.org/10.1007/978-1-4020-6787-7

[14] Gómez, T., Hernández, M., León, M. A, Caballero, R. "A forest planning problem solved via a linear fractional goal programming model", Forest Ecology and Management, 227(1-2), pp. 79-88, 2006. https://doi.org/10.1016/j.foreco.2006.02.012

[15] Díaz-Balteiro, L., Romero, C. "Forest management optimisation models when carbon captured is considered: a goal programming approach", Forest Ecology and Management, 174(1-3), pp. 447457, 2003.

https://doi.org/10.1016/S0378-1127(02)00075-0

[16] Samghabodi, A. S., Memariani, A., Amani, M. "Forest planning with use of mathematical model", Pajouhesh-Va-Sazandegi, 17, pp. 23-34, 2004.

[17] Chang, Y.-H., Wey, W.-M., Tseng, H.-Y. "Using ANP priorities with goal programming for revitalization strategies in historic transport: A case study of the Alishan Forest Railway", Expert Systems with Applications, 36(4), pp. 8682-8690, 2009. https://doi.org/10.1016/j.eswa.2008.10.024

[18] Kardoss, L. "Water Managerial and Environmental Aspects of Transportation", Periodica Polytechnica Civil Engineering, 38(2), pp. 205-217, 1994. [online] Available at: https://pp.bme.hu/ci/article/view/3789 [Accessed: 22 February 2020]

[19] Ijjas, F. "Integral water management", Periodica Polytechnica Civil Engineering, 58(2), pp. 105-112, 2014. https://doi.org/10.3311/PPci.7485

[20] Jay, S., Jones, C., Slinn, P., Wood, C. "Environmental impact assessment: Retrospect and prospect", Environmental Impact Assessment Review, 27(4), pp. 287-300, 2007. https://doi.org/10.1016/j.eiar.2006.12.001

[21] Komínková, D. "Environmental Impact Assessment and Application - Part 1", In: Jørgensen, S. E., Fath, B. D. (eds.) Encyclopedia of Ecology,, Elsevier, Oxford, UK, 2009, pp. 1321-1329.' https://doi.org/10.1016/B978-008045405-4.00052-5

[22] Keremane, G. B., McKay, J. "Successful wastewater reuse scheme and sustainable development: a case study in Adelaide", Water and Environmental Journal, 21(2), pp. 83-91, 2007. https://doi.org/10.1111/j.1747-6593.2006.00062.x

[23] Gikas, P., Liu, S., Papageorgiou, L. G., Konstantopoulou, F. "Optimal planning of water and wastewater management infrastructure for insular areas: the role of water reuse", Water Supply, 15(4), pp. 701-708, 2015.

https://doi.org/10.2166/ws.2015.017

[24] Lee, J., Bae, K.-H., Younos, T. "Conceptual framework for decentralized green water-infrastructure systems", Water and Environmental Journal, 32(1), pp. 112-117, 2018. https://doi.org/10.1111/wej.12305

[25] Mcheik, M., Toufaily, J., Haj Hassan, B., Hamieh, T., Abi Saab, M. T., ..., Al Hadidi, L. "Reuse of treated municipal wastewater in irrigation: a case study from Lebanon and Jordan", Water and Environmental Journal, 31(4), pp. 552-558, 2017. https://doi.org/10.1111/wej.12278
[26] DSDG "The Sustainable Development Goals", United Nations Department of Public Information, New York, NY, USA. [online] Available at: https://sustainabledevelopment.un.org/?menu=1300 [Accessed: 22 February 2020]

[27] Isfahan Regional Water Company "Zayandeh-Rud River Basin report", Ministry of Energy, Isfahan Regional Water Company, Isfahan, Iran, 2016. (in Persian)

[28] Statistical Center of Iran "The official website of the Ministry of Iran", [online] Available at: www.amar.org.ir [Accessed: 22 February 2020]

[29] Isfahan Water and Wastewater Company "Najafabad wastewater collection system report", Ministry of Energy, Isfahan Water and Wastewater Company, Isfahan, Iran, 2016. (in Persian)

[30] Najafabad Municipal "Statistical report", Najafabad, Iran, 2016. (in Persian)

[31] Safavi, H. R., Enteshari, S. "Conjunctive use of surface and ground water resources using the ant system optimization", Agricultural Water Management, 173, pp. 23-34, 2016. https://doi.org/10.1016/j.agwat.2016.05.001

[32] Isfahan Power Generation Management Company "Statistical report", Isfahan, Iran, 2016. (in Persian)

[33] Saaty, T. L. "The Analytic Hierarchy Process: Planning Priority Setting Resource Allocation", McGraw-Hill, New York, NY, USA, 1980.

[34] Lee, A. H. I., Chen, W.-C., Chang, C.-J. "A fuzzy AHP and BSC approach for evaluating performance of IT department in the manufacturing industry in Taiwan", Expert Systems with Applications, 34(1), pp. 96-107, 2008.'

https://doi.org/10.1016/j.eswa.2006.08.022

[35] Erkut, E., Tarimcilar, M. "On Sensitivity Analysis in the Analytic Hierarchy Process", IMA Journal of Management Mathematics, 3(1), pp. 61-83, 1991.? https://doi.org/10.1093/imaman/3.1.61

[36] Leopold, L. B., Clarke, F. E., Hanshaw, B. B., Balsley, J. R. "A procedure for evaluating environmental impact", U. S. Geological Survey, Washington, DC, USA, 1971. https://doi.org/10.3133/cir645

[37] Josimovic, B., Petric, J., Milijic, S. "The Use of the Leopold matrix in carrying out the eia for wind farms in Serbia", Energy and Environment Research, 4(1), pp. 43-54, 2014. https://doi.org/10.5539/eer.v4nlp43

[38] Buongiorno, J., Gilless, J. K. "Decision Methods for Forest Resource Management", 1st ed., Elsevier, Cambridge, MA, USA, 2003.

[39] Rathnayaka, K., Malano, H., Arora, M. "Assessment of Sustainability of Urban Water Supply and Demand Management Options: A Comprehensive Approach", Water, 8(12), Article number: 595, 2016. https://doi.org/10.3390/w8120595

[40] Delgado, M. G., Barredo Cano, J. I. "Sistemas de Informacion Geografica y Evaluacion Multicriterio en la Ordenacion del Territorio" (Geographic Information Systems and multicriteria evaluation in land management), 2nd ed., Grupo Editorial RA-MA, Madrid, Spain, 2006. (in Spanish) 